\title{
The Spirit of Saskatoon will Die Unless ...
}

\author{
JOHN D. DENNISON*
}

... the open and genuine dialogue among the various interested parties in Saskatoon be continued on a regular and systematic basis.

One of the most encouraging aspects of the Forum was the discussion among educators and representatives of the private sector regarding the critical and coordinated role each must play if Canada is to compete successfully in the world economic marketplace. The agenda in Saskatoon was broad, and as the focus was not rigidly defined, the discussion groups soon adopted a free wheeling approach to the issues on the table. Despite an element of initial antagonism and misunderstanding, a different climate soon began to emerge. The three day dialogue eventuated in a deeper and more informed appreciation of the frustrations of both groups. It could be said that the Forum concluded at a stage at which business representatives and educators were ready to explore a truly coordinated plan for the development of Canada's human resources in an attempt to secure its economic and cultural future.

A second level of dialogue which emerged in Saskatoon was between those from the university and the college sector. From the discussions on accessibility and management of the system it was inevitable that the roles of each sector would become more clearly defined, and in the process there would emerge a better realization of the essential complementarity of colleges and universities in the delivery of educational programs.

All interest groups at Saskatoon seemed to emerge from the unique three day experience with one general conclusion - that Canada already possessed a fully comprehensive and well established postsecondary educational system, with the leadership to meet any challenge. The real question, however, was how to make the system work more effectively. Perhaps with more creative and constructive ideas for improved coordination, Canada's colleges, universities and vocational institutes, together with a rapidly emerging distance education component, would finally realize their capacity to meet the needs of both industry and society at large, to the ultimate benefit of the nation. There was much support at the Forum for the belief that Canada's greatest resource was its people, young and old, and that in the new information-based global economy the key to success would be the widest and most successful exploitation of the talents of its people.

Greater accessibility for all Canadians, including the traditionally disadvantaged, mature students, women, native people, and residents of isolated regions, 
was possible only if the established institutions were to deliver educational programs under conditions designed more to accommodate the needs of the student than the convenience of the institutions.

For those at Saskatoon from various levels of government, both elected and from the civil service, the dialogue generated another important message - that the current state of higher education funding cannot continue. Refusal to assume responsibility for the fiscal health of the system, and its corollary, counterproductive assignment of blame for its weakened condition, must be addressed without prejudice by both levels of government if Canadian colleges and universities are to achieve maximum productivity and quality of service. The clear message from Saskatoon was the need for a national strategy for higher education, as distinct from either a provincial or a federal design. In 1988, colleges and universities in this country pursue, and must continue to pursue, national and international priorities if Canada is to compete economically with similarly developed nations. Provincial parochialism, or federal "politics," at the expense of a strong postsecondary education system, can spell only disaster for this nation's economic future.

In just what form, or under which arrangement, a national higher education strategy might be concluded was not made clear at the Forum, nor was such a result intended. The real value from the conference was the opening of a dialogue on the issue, unhampered or inhibited by circumstances of history. It is to be hoped that the Council of Ministers will approach their discussion of the report of the Forum in similar vein.

The National Forum in Saskatoon may enter Canadian history books as the critical reference point in the creation of a new era for the management, planning, and financing of the nation's higher education system. It may also be dismissed and ignored by all but the participants as just another unproductive exercise in an attempted revitalization of another classical victim of federal-provincial arrangements in Canada. In this observer's view the choice will be set largely by the amount, commitment to, and quality of continued dialogue among the interested parties who contributed to the "spirit of Saskatoon." 